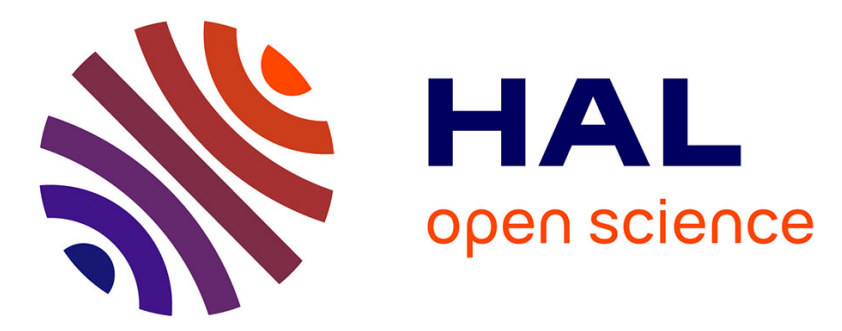

\title{
Delos archaeological marbles: A preliminary geochemistry-based quarry provenance study
}

T. Vettor, V. Sautter, S. Pont, C. Harivel, L. Jolivet, Isabelle Moretti, Jean-Charles Moretti

\section{- To cite this version:}

T. Vettor, V. Sautter, S. Pont, C. Harivel, L. Jolivet, et al.. Delos archaeological marbles: A preliminary geochemistry-based quarry provenance study. Archaeometry, 2021, 10.1111/arcm.12655 . hal-03131193

\section{HAL Id: hal-03131193 \\ https://hal.science/hal-03131193}

Submitted on 8 Apr 2021

HAL is a multi-disciplinary open access archive for the deposit and dissemination of scientific research documents, whether they are published or not. The documents may come from teaching and research institutions in France or abroad, or from public or private research centers.
L'archive ouverte pluridisciplinaire HAL, est destinée au dépôt et à la diffusion de documents scientifiques de niveau recherche, publiés ou non, émanant des établissements d'enseignement et de recherche français ou étrangers, des laboratoires publics ou privés. 


\section{Delos archaeological marbles: A preliminary geochemistry-based quarry provenance study}

Vettor T. ${ }^{1}$, Sautter V. ${ }^{1}$, Pont S. ${ }^{1}$, Harivel C. ${ }^{2}$, Jolivet L. ${ }^{3}$, Moretti I. ${ }^{3}$ and Moretti J.C. ${ }^{4}$

${ }^{1}$ Institut de Minéralogie, de Physique des Matériaux et de Cosmochimie ( IMPMC), UMR CNRS 7590, Muséum National d'Histoire Naturelle, Sorbonne Université 61 Rue Buffon, 75005, Paris, France (tommy.vettor@edu.mnhn.fr; violaine.sautter@mnhn.fr; sylvain.pont@mnhn.fr)

${ }^{2}$ PréTech, Université Paris Nanterre, 21, Allée de l'Université, 92023 Nanterre Cedex, France (carine.harivel@gmail.com)

${ }^{3}$ ISTeP, UMR CNRS 7193, Sorbonne Université, 4 Place Jussieu, Paris Cedex 05, 75252, France (laurent.jolivet@sorbonne-universite.fr; isabelle.moretti@sorbonne-universite.fr)

${ }^{4}$ CNRS, Institut de Recherche sur 1'Architecture Antique, Université Lumière Lyon 2, MOM, 5/7 rue Raulin,Lyon Cedex 07, 69365, France (jeancharles.moretti@mom.fr)

Abstract

This paper presents for the first time chemical data on the ancient (Antiquity period) marble quarries of Delos Island and some architectural marbles from its famous and exceptionally well-preserved archaeological site. Delos geological substratum is mostly composed of granite, including very few decametric marble enclaves. However, ancient Delian architecture is dominated by gneiss and marbles. A large quantity of marble had thus to be imported from neighbouring Cycladic Islands and continental Greece. Their provenances remain mostly unknown. Several analytical methods have been developed in archaeometry for years to determine the origin of marbles, but they are generally destructive. This paper reports a methodology based on a hand-held portable X-ray fluorescence (pXRF) analyser to detect major and trace elements often used in provenance studies. Drawbacks of using those elements for marble provenance and analytical limitations attached to portable instruments were frequently discussed. Here the usefulness of pXRF for marble provenance research was tested in association with principal component analysis (PCA). Two 
artefacts of presumed Delian origin were selected and the results showed that one of them came undoubtedly from a Delian quarry while the other one was not of local origin. This protocol appeared to be a powerful tool when conventional destructive analyses are precluded.

Keywords: Archaeometry, marble provenance, Delos, pXRF spectrometry, Antiquity period, Principal Component Analysis

Declarations: There is no conflict of interest

Data are available by request to the first author

Acknowledgment: The authors would like to thank the four year ANR program Geology and Architecture at Delos (GAD) for granting this work. We also thank the Cyclades Ephorate for giving us the authoriza-tion to sample and analyse marbles in Delos Island.

We are grateful to the two anonymous reviewers who highly contributed to the improvement of this article.

\section{Introduction}

Due to its remarkable mechanical and aesthetic properties, marble has been widely used during Antiquity in architecture and sculpture. Local marble quarries often provided construction material for vicinity monuments but a large amount of blocks were also exported to other sites throughout ancient commercial routes. Thus, numerous marbles coming from Cycladic Islands and the Attique region were spread all around the Mediterranean area during Antiquity. There- fore, the study of marble provenance can trace back ancient commercial routes. Moreover, the operating periods of the main Mediterranean quarries being known, marble provenance can strengthen the understanding of marble trading chronology and monuments construction. Commonly used visual inspections often lead to misidentification, especially for white marbles, and thus to incorrect provenance assignments. Consequently, marble provenance is the subject ofa large amount of studies for many years.

Greek marble provenance of archaeological artefacts (monuments and sculptures) has been studied for more than a century, starting with Richard Lepsius (1890) work, which rapidly became a reference in marble provenance investigations. To date, the most reliable way to identify the provenance quarries of ancient marble artefacts combines three destructive techniques: mineralo- 
petrographic examination of thin sections with optical microscopy, scanning electron microscopy coupled with energy dispersive spectrometry (SEM-EDS; Lapuente et al. 2000; Capedri and Venturelli 2004; Pensabene et al. 2012; Ricca et al. 2015); geochemical determina-tion of trace elements (Green et al. 2002; Poretti et al. 2017) and isotopic analyses of carbon, oxygen, and strontium (Tykot et al. 2002; Brilli et al. 2005; Attanasio et al. 2006; La Russa et al. 2013; Ricca et al. 2014; Antonelli and Lazzarini 2015). The increasing need for non-destructive investigations (Lazzarini et al. 1980; Calligaro et al. 2013; Magrini et al. 2016) has become a major issue, as sampling in archaeological building is in most cases restricted in view of their uniqueness.

Non-destructive protocols offer the possibility to obtain preliminary information on Delos artefacts before being allowed to implement further complementary destructive techniques. The present study establishes the very first chemical and grain size database of Delos Island marbles. So far, Delian marble identification was exclusively based on visual criteria, which lead to debated provenances. The chosen protocol is based on non-destructive chemical analyses using portable x-ray fluorescence ( $\mathrm{pXRF}$ ) and optical microscopy field observations. Data were compared and processed using the principal component analysis (PCA) statistical tool. Such a methodology allows rapid preliminary diagnoses. This study merely intends to test it.

PXRF has already been used on Delos Island but exclusively for ceramic and statue pigments (Karydas et al. 2009). Practically speaking, this technique is fast, non-destructive, easy to use, economical, and requires minimal sample preparation. Analyses were performed on two sets of materials: (i) geological samples coming from known antique Greek marble quarries. It includes Delian quarries never studied so far; (ii) two selected groups of antique building stones in Delos archaeological site. One comes from a wall constructed next to a marble quarry with identical macroscopic appearance. The aim is to prove its Indigenous provenance. The other one comes from a monument and was macroscopically described as an Indigenous marble. This provenance needs to be verified.

\section{Archaeological and geological context}

\subsection{Archaeology}

Delos, the mythological Apollo birthplace located in the centre of the Cycladic archipelago (Fig. 1), is well known for its exceptionally well-preserved archaeological site. This small island became a famous religious sanctuary during 
the seventh century BCE and then a major free harbour, becoming thus a key trading point during the Antiquity. Merchandises from Cyclades, Attique, and even fur-ther (Italy, Egypt, etc.) were circulating through Delos harbours (Ecole Française d'Athènes 2005).

\section{Figure 1}

Excavation by the French School of Athens (EFA) started in 1872. Ruins of more than threemillennia of human occupation with an acme at the end of the first century BCE are visible in the north-western part of the island. The antique city has expanded on 80 hectares regarding the 350 of the island surface but only 30 of them have been excavated so far (figure 1 in supplementary material). Religious, commercial, and residential buildings appear to be essentially built up with granite, gneiss, and marbles. Preliminary estimations indicate that a minimum volume of $500,000 \mathrm{~m}^{3}$ of marble was necessary to account for the archaeological material excavated so far.Delos was a key trading point, so the possibilities for marble provenance are multiple.

Building site accounts, generally carved within marble slabs, mention exchanges with Aegean Islands such as Paros, as well as continental Athenian region (Fig. 1). These priceless archives, complementing preliminary macroscopic examination, served as guides to this geochemical investigation. Such a study will thus eventually help to document religious and commercial relationships between Delos and the neighbouring islands as well as continental Greece.

\subsection{Geology}

Delos, one of the smallest Cycladic Islands at $5 \mathrm{~km}$ long and $1 \mathrm{~km}$ wide, is located between Mykonos and Rhenia in the Aegean Sea. It is mainly a type-I granitic pluton intruding gneiss basement (Altherr and Siebel 2002; Fig. 1). It belongs to the Mykonos-Delos-Rhenia metamorphic complex exhumed as high temperature gneiss dome during back arc extension (20 to $8 \mathrm{Ma}$ ). The later results from slab retreat below the North Cycladic Detachment System (Faure et al. 1991; Lee and Lister 1992; Lucas 1999; Jolivet et al. 2010; Denèle et al. 2011). This extension stage ends up with the syn-kinematic piercing of the dome by granitic plutons during mid Miocene (11.1-9.5 Ma) (Denèle et al. 2011 and reference therein). In Delos, graniteoutcrops over $70 \%$ of the island from its central to its southern parts 
and is also the dominating rock within the adjacent island Mykonos (Cayeux 1911). It intrudes the gneissic Cycladic base-ment of Hercynian age (327 \pm 4 Ma to $295 \pm 44$ Ma; Keay 1998), forming $25 \%$ of the island in its northern part. Gneiss outcrops dominate in adjacent Rhenia Island (Fig. 1). Within Delos granitic pluton, diversified highly deformed metamorphic country rocks from the Cycladic Blue Schist Unit (Blake et al. 1981) appear as small metric to decametric enclaves forming approximately $5 \%$ of the island. They consist of interbedded foliated layers of marble, amphib- olite, and schist, initially (55-35 Ma) buried under HP-LT conditions (blue schist facies) then (30-15 Ma) retrograded during exhumation under HT-LP conditions (amphibolite/green schist facies; Parra et al. 2002; Jolivet et al. 2004). At least five ancient marble quarries (Fig. 1), about hundred meters long, have been identified throughout Delos Island (Fraisse and Kozelj 1991; Chatzidakis et al. 1997; Hadjidakis et al. 2003; Kokkoru-Aleura et al. 2014). Preliminary volume estimations determined from topography study of the quarries give $174,000 \mathrm{~m}^{3}$ extracted mate- rial. In other words, Delian extracted marbles are three to five times less than the required volume to account for the archaeological building excavated so far.

\section{Materials and analytical techniques}

\subsection{Geological samples: quarry database}

Petrographic and isotopic databases including hundreds of marble analyses from the major and minor quarries exploited during Greek and Roman Antiquity are numerous (Antonelli and Lazzarini 2015 and reference therein) compared to minor and trace element databases (Matthews 1997; Green et al. 2002). Moreover, apart from general information about the most famous marble quarries in Cyclades Archipelago (Naxos, Paros, Tinos) and Attica (Pentelic and Hymettus), there was, prior to this study, no database for Delos quarries.

For the purpose of this study, a preliminary database including a total of twenty-two marbles from continental Greece and Cycladic Islands was designed. Two Attica samples were collected, both from Kareas quarry in Mount Hymettus. Twenty samples were collected in Cycladic Islands: two in Paros taken near Chorioudaki and Marathi (marble called lychnite); four in Naxos from Melanes, Naxos-Marmor Abbau Mountain and Appolona; seven in Tinos from Kardiani, Isternia, Marlas, Koumaros, and near Kionia. The seven remaining samples come from the five ancient marble extraction outcrops of Delos (Fig. 1, Hadjidakis et al. 2003). The first two quarries Qm1 and Qm2 are located outside the archaeological site respectively in SW and SE of the island. One sample was collected in each location. The other three quarries Qm3, Qm4, and Qm5 are 
within or close to the site. Qm3 had been excavated from Ghlastropi Hill overlooking the southern area of the theatre district. Two types of marble were sampled there. Qm4 is located within the theatre district where one marble was sampled. Two marbles were sam- pled from Qm5 adjacent to the Inopos reservoir. Those seven Delian marbles are presented and described in Figure 2.

\section{Figure 2}

\subsection{Archaeological building stones}

Two sets of archaeological artefacts were selected for the purpose of the present work.

The first one comes from a wall in an Inopos district house (figure 3A), adjacent to marble quarry Qm5. It has been identified from macroscopic criteria as being very similar to the adjacent marble outcrop (figure $2 \mathrm{G}$ ) visible on the west side of the Inopos water reservoir. Indeed both the outcrop and Inopos walls present a very thin yellow homeoblastic marble.

The second one comes from the portico of Philip V of Macedonia, built on Delos around 210 B.C. It is made out of a bluish heteroblastic marble with very large calcite/dolomite crystals (figure 3B), initially assumed to be indigenous (Vallois, 1923). Nevertheless, this local provenance has never been demonstrated and the marble aspect (colour, grain size) calls Delian origin into question.

\section{Figure 3}

\subsection{Analytical techniques}

\subsubsection{Maximum grain size measurements (MGS)}

One of the most commonly used parameters in marble provenance studies is the Maximum Grain Size (MGS) of the rock-forming calcite and dolomite crystals. Attanasio et al. (2006) published the most comprehensive database of MGS with more than 1,300 samples. Measurements are generally based on a microscopic examination of thin sections. Here MGS of the calcite grains were directly measured in the field with a portable microscope DINO-LITE model AM7515MZT. This model is equipped with a linearpolarizer and an IR cut filter over $650 \mathrm{~nm}$ with a x20 to x220 magnification capacity. Actually, if marbles such as the Hymettus one are homogeneous with respect to MGS criteria, other marbles can present heterogeneities. It is then necessary to measure several MGSs. Statistically speaking MGS measurements used in this article are based on six 
pictures per object. The main difficulty of this analyse is to distinguish mineral grain boundaries from fractures and natural calcite cleavages.

\subsubsection{Portable $X$-rays fluorescence ( $p X R F)$. analyses}

Non-destructive in-situ analyses of twenty-two samples were performed with a pXRF gun model Niton XL3 from THERMOFISHER. This model uses a silicon drift detector with a resolution of $160 \mathrm{eV}$. It is equipped with a silver anode (Niton 147-00X) and a 0,127 mm beryllium exit window. The spectra were collected at $50 \mathrm{kV}$ and $40 \mu \mathrm{A}$ with a counting time of $120 \mathrm{~s}$ (4 filters of $30 \mathrm{~s}$ each) using mining $(\mathrm{Cu} / \mathrm{Zn})$ mode. The analysis window is circular and has a diameter of $8 \mathrm{~mm}$. According to the selected analysis settings, this pXRF provides concentrations of the elements going from $\mathrm{Mg}$ to $\mathrm{U}$. Elements lighter than $\mathrm{Mg}$ cannot be detected due to the background signal. Background increases when atomic number decreases since it varies approximately as $\frac{1}{Z^{2}}$ (Shackley, 2011).

Compared to lab-instrument, hand-held analysers exhibits a number of limitations such as atmosphere X-ray absorption. Lab-based XRF can work in helium filled chambers while pXRF has to deal with the air absorption at low atomic number (especially for titanium and lighter elements). Argon among others is known to affect calcium and potassium measurement since it absorbs a part of their X-rays (Shackley, 2011). The technique is also sensitive to surface morphology of the samples, they need to be as flat as possible. Indeed the investigation depth fluctuates as a function of the analysed element. For instance, maximum depth is $3 \mathrm{~mm}$ for $\mathrm{Nd}$ analysis while it is only $20 \mu \mathrm{m}$ for $\mathrm{Mg}$. This range of maximum depths corresponds to the depths where $90 \%$ of the signal is attenuated. Moreover surface chemical alteration on weathered surface may distort composition of the pristine marble underneath. Carefully selecting the surface to be analysed is thus critical to acquire interpretable data. Ideal surfaces should be flat, as fresh as possible with minimal irregularities. Finally compared with a lab-based instrument, pXRF has lower accuracy (minor closeness to the true value) and lower precision (less reproducible). For accuracy purposes, calibration targets are required as standards. Up to five spots per sample were analysed to strengthen the representativeness and decrease therefore the effect of mineral heterogeneities. A stack of two measurements was applied to each spot for reproducibility purpose.

\subsubsection{Inductively Coupled Plasma (ICP) analyses and pXRF calibration}

Quarry samples were analysed at SARM laboratory in Nancy (France) with Inductively Coupled Plasma analyses after being dissolved with a lithium-borate fusion $\left(\mathrm{LiBO}_{4}\right)$ protocol. Major elements were measured with Optical Emission Spectrometry (ICP-OES) using the Thermo Fischer Icap 6500 spectrometer. Minor 
and trace elements were analysed with Mass Spectrometry (ICP-MS) using Thermo Fischer Icap Q spectrometer. The standards used for analyses are basalt BR, anorthosite AN-G, serpentinite UB-N, diorite DR-N, granite GH and limestone CAL-S. The global analysis protocol is described by Carignan et al. (2001).

In this work the accuracy of pXRF analyses was statistically evaluated by a comparison of data acquired with $\mathrm{pXRF}$ and ICP on database marbles.

Four marble calibration targets analysed by ICP were selected from the quarry database. Those standards were analysed with pXRF before and after each set of measurements in order to monitor possible instrumental deviations.

Marbles showing colour differences within a single sample were analysed separately. This comparison aims to verify if $\mathrm{pXRF}$ concentrations are lineary linked to the ICP values. If not, it would have been impossible to calibrate pXRF data with ICP values. Since ICP analyses were made on marble powders, ICP data were compared with pressed powder pXRF analyses. Thus, it has been ensured that these analyses were not skewed by the grain size and the chemical heterogeneity of the samples mineralogy.

\subsubsection{Principal Component Analyses (PCA)}

Calibrated chemical analyses and MGS were integrated in a powerful statistic tool: the principal component analysis (PCA). PCA is commonly used to reduce the dimensionality of a data set, expressing it as a combination of a small number of linearly independent variables, the so-called "principal components" (Davis 1986). This powerful comparison tool uses the variance of each variable to discriminate between items rather than matching them two by two. PCA is thus suitable for quarry provenance investigations and has already proved its worth for obsidian (Forster and Grave 2012) and marble (Poretti et al. 2017). In PCA of XRF data, variables correspond to analysed elements. It is known that calcite grain size depends on pressure, temperature, and strain conditions whereas marble chem ical composition depends on the initial limestone chemistry and fluid-rock interactions during later metamorphic history. MGS and chemical data are thus considered to be independent from each other and MGS constitutes an additional variable in PCA.

PCA calculation uses the variance of each variable to compare marble samples and thus estimates the correspondences between themselves. Resulting diagrams are two dimension plots representing percentages of variance. They show one ellipse per marble plotted more or less distant from each other depending on their variance similarities. The ellipse size is representative of the global variance dispersions between variables. The greater fluctuations in a single sample 
variables the bigger its variance fluctuations and its ellipse will be. Therefore a small ellipse indicates a well defined and homogeneous marble with low dispersion in its variables. One principal component (PC) is affected to each dimension. There are as many PC as number of variables. The first three principal components (PC1, PC2 and PC3) contain most of the variance. Therefore PCA often focusses on those three ones since using PC4 or above would base analyses on very small variances. However it is sometimes interesting to consider them when the first components are noised. Variables operate differently in each principal component, so it is possible to switch from one to another in order to make better comparisons. For example, on a marbleweathered surface, silicon can be over estimated, it can thus be interesting to decrease silicon weight by changing a PC for a less sensitive one to Si content.

PCA can then assign the studied artefact to the compositional class of one or several marbles of known composition by the use of database pXRF and MGS data.

\section{Results and discussion}

\subsection{Selected parameters for PCA processing}

MGS analyses show a wide range of variation from $200 \mu \mathrm{m}$ to few centimetres within the reference database. Figure 4 shows a boxplot of MGS values for the twenty-two database samples and the two archaeological building marbles. It is built from the median, the $25^{\text {th }}$ and $75^{\text {th }}$ percentiles and the minimum and maximum MGS values.

Homeoblastic fabric where calcite/dolomite crystals have equal dimensions are observed for Hymettan, Tinian and Parian database samples. The Hymettan marble have MGS around $200 \mu \mathrm{m}$. Tinian marbles are generally fine-grained with quite low MGS with a maximum MGS around $1 \mathrm{~mm}$ excepted those from Koumaros quarry with higher MGS of $2 \mathrm{~mm}$ and even $13 \mathrm{~mm}$ due to their proximity with a granite intrusion (Carignan et al., 1997). The two Parian samples show a $3 \mathrm{~mm}$ MGS. One Delian marble from the Inopos quarry (Qm5, Hadjidakis et al., 2003) is fine grained with MGS of $0.8 \mathrm{~mm}$ identical to MGS from Inopos wall marble. Philip V portico marble shows large heteroblastic texture with centimetric crystals up to $12 \mathrm{~mm}$. Naxian and most of the Delian marbles show heteroblastic texture calcite/dolomite crystals exhibiting variable dimensions. Regarding Naxos samples, MGS vary between 2 and $7 \mathrm{~mm}$ while Delian marbles are mainly between 3 and $20 \mathrm{~mm}$. The $20 \mathrm{~mm}$ MGS marble is a unique marble from Qm2 quarry located outside the archaeological site, south-east of Mount 
Cynthus ( Hadjidakis et al., 2003). It can be identified in the architecture as it has heterogranular texture with large visible bluish centimetre-sized crystals.

\section{Figure 4}

Portable XRF analyses of the studied quarry database showed that twentytwo elements ( $\mathrm{Sb}, \mathrm{Cd}, \mathrm{Pd}, \mathrm{Ag}, \mathrm{Mo}, \mathrm{Nb}, \mathrm{U}, \mathrm{Th}, \mathrm{Rb}, \mathrm{Bi}, \mathrm{As}, \mathrm{Se}, \mathrm{Au}, \mathrm{Pb}, \mathrm{W}, \mathrm{Zn}, \mathrm{Cu}$, $\mathrm{Ni}, \mathrm{Co}, \mathrm{V}, \mathrm{Ti}, \mathrm{Al}$ ) over the forty-one analyzable with the used $\mathrm{pXRF}$ program were not detected due to the previously mentioned detection limits (§3.3.2). Magnesium was exclusively detected in two marbles whose ICP analyses showed a rather high concentration of $\mathrm{Mg}(16 \% \pm 0.3 \%)$ correlated with a $20 \% \pm 1.7 \%$ Ca decrease compared to calcitic marbles. Therefore it appeared useless to consider magnesium since the negative $\mathrm{Mg}-\mathrm{Ca}$ correlation pointed to a dolomite-rich $\left(\mathrm{CaMg}\left(\mathrm{CO}_{3}\right)_{2}\right)$ marble composition. The seven following elements $\mathrm{Sn}, \mathrm{Zr}, \mathrm{Y}, \mathrm{Mn}, \mathrm{Cr}, \mathrm{P}$, K were detected in a few marbles but are too close to the detection limit with an analytical precision around $50 \%$ of the concentration value in this case (Potts et al., 1984). Among the eleven remaining elements, $\mathrm{Nd}, \mathrm{Pr}, \mathrm{Ce}, \mathrm{La}$ and $\mathrm{Ba}$ were detected, but the variability of their concentrations was smaller than the uncertainty. $\mathrm{Sr}, \mathrm{Fe}, \mathrm{Ca}$, $\mathrm{Si}, \mathrm{Cl}$ and $\mathrm{S}$ concentrations presented nevertheless a good variability throughout the database and were thus selected for the purpose of this study. Chemical variations are due to $\mathrm{Ca}$ substitutions within calcite lattice crystal by elements such as $\mathrm{Fe}$ and $\mathrm{Sr}$ whose ionic radii are close to $\mathrm{Ca}$ one. On the contrary $\mathrm{Si}, \mathrm{Cl}$ and $\mathrm{S}$ do not substitute to $\mathrm{Ca}$ but would eventually diagnose accessory minerals at micrometre scale such as quartz, micas, and sulfides. Being irregularly distributed within the analyzed samples, they deeply affect the results (Matthews, 1997).

\subsection{Fresh vs. weathered surface}

This marble provenance study was conducted on weathered surfaces of archaeological and quarries marbles, artefacts sampling being precluded. Therefore, it is necessary to understand how surface weathering affects major and trace elements concentrations.

Database pXRF analyses were carried out on both fresh cut sections and clean weathered surfaces when they were available. On these criteria, fifteen marbles were finally selected.

The resulting diagram (figure 2 in supplementary material) shows clear chemical differences between fresh and weathered surfaces whatever their provenance. Weathered surfaces are impoverished in calcium and enriched in silicon and iron while strontium concentration seems to be constant. When surfaces are weathered, a micro-surface-porosity is created by dissolution and can be filled with a brownish 
soft material corresponding chemically to an increase of $\mathrm{Si}$ and $\mathrm{Fe}$ and a slight decrease in $\mathrm{Ca}$. This could indicate the presence of phyllosilicates or clay minerals characteristics of alteration processes at rock/atmosphere interface (Garcia-Vallès et al., 2000).

Whether for fresh or weathered surfaces, $\mathrm{Ca}, \mathrm{Sr}, \mathrm{Si}$ and $\mathrm{Fe}$ elements have similar trends while $\mathrm{S}$ and $\mathrm{Cl}$ ones are random (figure 2 in supplementary material). Consequently, the former four elements were used for pXRF data processing bearing in mind that $\mathrm{Si}$ and $\mathrm{Fe}$ concentrations are over-estimated, while $\mathrm{Ca}$ is slightly under-estimated for altered surfaces.

From fresh to weathered surfaces calcium decreases of about $15000 \mathrm{ppm}$ which is not significant compared to the $150000 \mathrm{ppm}$ difference observed between marble and dolomite-rich marble in this database (figure 2 in supplementary material, one Naxos marble, NAX-MELA-1, is dolomitic). Consequently, weathering surfaces did not impact dolomitic marble identification in this study.

Stability of strontium concentration demonstrates how useful this element can be in $\mathrm{XRF}$ analyses as its concentration seems to remain unchanged on weathered surfaces. It can be highly discriminant when a marble has a particular $\mathrm{Sr}$ concentration as, for example, it is the case of Göktepe marble (Turkey) with its high $\mathrm{Sr}$ content which makes this marble easy to identify with XRF (Magrini et al., 2016).

\section{Supplementary material: Figure 2}

\subsection{Calibration on ICP data}

The four remaining elements of interest $\mathrm{Ca}, \mathrm{Sr}, \mathrm{Si}$ and $\mathrm{Fe}$ were calibrated using the ICP analysis of twenty-one marbles of the quarry database as stated in §3.3.3. Figure 3 in supplementary material shows how correction equations were obtained. A linear regression was applied after plotting ICP data versus pXRF ones. The equations present a coefficient of determination $\mathrm{R}^{2}$ above 0.97 . Regarding the good obtained $\mathrm{R}^{2}$ values, regression equations are applied to pXRF data to calibrate them to ICP values. Calibration data are available in Table 1 in supplementary material.

ICP errors were calculated from the percentage of uncertainty given by SARM laboratory. Each powder was analysed approximately ten times with pXRF in order to analyse reproducibility and to determine the errors on measured values.

\section{Supplementary material: Figure 3}


Percentiles, minimum and maximum values of calibrated pXRF data are represented in figure 5. Calibrated pXRF data show quite constant $\mathrm{Ca}$ concentrations in almost each locality. However three outsiders show a large $\mathrm{Ca}$ decrease. Those three marbles coming from Delos (DEL-Qm5-2), Naxos (NAXMELA-1) and from Inopos wall correspond to dolomitic marbles.

Delos, Tinos, Paros, Naxos and Hymettus samples show a low $\mathrm{Sr}$ concentration around $150 \mathrm{ppm}$. One Tinos marble (TIN-ISTE) and Philip V portico marble are outside the global trend with $400 \mathrm{ppm}$. Sr measurement being very efficient with pXRF (Magrini et al., 2016), those observed variations are thus crucial to identify marble provenance in the present study.

Si concentrations do not exceed 15000 ppm except one Delian marble (DELQm5-2), one Tinian marble (TIN-ISTE) and the artefact from Inopos wall. Tinian marble from Isternia was thus characterised by both its high $\mathrm{Si}$ and $\mathrm{Sr}$ content.

Concerning Fe, three marbles emerge with concentrations over 2500 ppm: DELQm5-2, NAX-MELA-1 and the Inopos wall marble.

\section{Figure 5}

\subsection{Marble provenance tested on two archaeological artefacts}

Four marble standards were analysed before and after each pXRF analyses session. No instrumental drift was observed. Focusing on clean plane surfaces helped to reduce X-ray scattering but such surface conditions are difficult to find on the field and sometimes only irregular surfaces were available and analysed with pXRF. PCA was performed with five variables: MGS, Ca, Sr, Si and Fe. Each PCA includes the fifteen previously described marbles and the archaeological artefacts

The method was first tested with marble blocks from the Inopos district wall previously described (\$3.2). The wall marble and the adjacent quarry Qm5 share the same macroscopic features (figures $2 \mathrm{G}$ and $3 \mathrm{~A}$ ). Three blocks were analysed and appear as a black ellipse in PCA diagram of figure 6. The ellipse superimposes the Delian cluster Qm5-2 and a Naxian one NAX-MELA-1 then pointing to two possible provenances. If both are dolomitic marbles, their MGS are very different. Indeed, Delian marble exhibits a MGS of $800 \mu \mathrm{m}$ while Naxian one shows a MGS of $2 \mathrm{~mm}$. Inopos wall and marble from Qm5 quarry having both an $800 \mu \mathrm{m}$ MGS, this parameter is critical to eliminate the Naxian provenance. This pXRF approach confirms that marble of the Inopos wall comes from the nearby Delian quarry according to the current reference database. 


\section{Figure 6}

The second example was taken from three marble artefacts of the Philip V portico (\$3.2) showing the same macroscopic features. The resulting PCA diagram (figure 7) shows a clear distinction between all the reference quarry ellipses and the Philippe V portico ellipse. The portico ellipse does not intersect any of the five Delian blue ellipses. Furthemore the two other non-plotted Delian marbles are strontium-poor while Portico one is Strontium-rich. Therefore, the portico is obviously not made out of Delian marble. With respect to the other localities, this PCA indicates that it is not built either with any marble referenced in the database. This marble characterized by a great $\mathrm{Sr}$ concentration and a high MGS might come from a non-yet-referenced Cycladic or continental marble. This example illustrates the potential of $\mathrm{pXRF}$ analyses for disqualifying indigenous marble provenances.

\section{Figure 7}

\section{Conclusion}

Until now, determination of Delos marbles origin was limited to visual considerations leading to misinterpretations. This non-destructive study showed the efficiency of a Principal Component Analysis treatment applied on both Maximum Grain Size and portable X-Ray Fluorescence data for marble provenance studies when micro-destructive analyses such as mass spectrometry or isotopic analyses were precluded. Despite limitation of pXRF, it allowed to answer the questions about local vs. imported provenance of two artefacts from Delos archaeological site. Local provenance of Inopos wall marble has been confirmed while the indigenous provenance of Philip V portico marble has been refuted. When unambiguous conclusions cannot be drawn, it is still possible to reduce provenance possibilities as the ellipse of studied marble do not overlap all the other quarry ellipses. The present protocol is therefore an efficient alternative to destructive analyses in order to get preliminary results and provenance conclusions.

Finally this work provided preliminary chemical data and MGS information about ancient marble quarries of Delos Island for the very first time. MGS measurements displayed a large range of values thus highlighting large variability of Delian marbles. The four studied chemical elements did not show such significant variations except for one single dolomitic marble. Micro-destructive analyses such as Rare Earth Elements and isotopic $\left(\delta^{18} \mathrm{O}, \quad \delta^{13} \mathrm{C},{ }^{87} \mathrm{Sr} /{ }^{86} \mathrm{Sr}\right)$ measurements might highlight further variability within Delian marble quarries. 


\section{Captions for figures and tables}

Fig. 1 Simplified geological map of Cycladic Islands. (Basemap comes from Esri, Garmin \& GEBCO)

Fig. 2 Marble from Delos quarries. Macroscopic presentation of Delos rough and sawed marble surfaces, presented respectively in the left and right pictures. Hadjidakis et al., (2003) nomenclature is used to name marble quarries from Qm1 to Qm5. (A) Qm1 marble is located in the south west part of the island, it contains a white to blue/grey homeoblastic marble. (B) Qm2 is located in the south east of Mount Cynthus, it contains a particular heteroblastic white marble with large centimetre-sized white and blue crystals. (C, D) Qm3 marble outcrops are located in Ghlastropi hills and are represented by two white heteroblastic marble. (E) Qm4 is located behind the theatre, it is made of a white homeoblastic marble. (F, G) Qm5 is located in the Inopos district, it contains a white homeoblastic marble (F) and a thin yellow to orange marble $(\mathrm{G})$

Fig. 3 Marble from two selected artefacts. Macroscopic presentation of the two studied archaeological structures. Left and right pictures show respectively a general view and a field microscope picture of their surfaces. (A) Studied Inopos wall pavers are made of a yellow to orange homeoblastic marble with inframillimetric calcite/dolomite crystals) (B) Philip V portico marble is an heteroblastic blue to grey marble with large centimetre-sized calcite/dolomite crystals.

Fig. 4 Maximum grain size (MGS) diagram built from the reference database. Median, $25^{\text {th }}$ and $75^{\text {th }}$ percentiles, minimum and maximum values are represented respectively by central line, box limits and whiskers. Consequently boxes constitute a $50 \%$ clustering of MGS data. Circles correspond to outsiders with a much higher MGS than the other marbles for a same locality

Fig. 5 Boxplot of $\mathrm{Ca}, \mathrm{Sr}, \mathrm{Si}$ and $\mathrm{Fe}$ concentrations measured with pXRF on the weathered surface of database, Philip V portico and Inopos wall. Median, $25^{\text {th }}$ and $75^{\text {th }}$ percentiles, minimum and maximum values are represented respectively by central line, box limits and whiskers. Consequently boxes constitute a $50 \%$ clustering of data. Circles correspond to outsiders with a much higher concentration than the other marbles for a same locality. Sample nomenclature is explained in $\S 3.1$. Values are in ppm

Fig. 6 Principal component analysis (PCA) diagram using 5 variables $(\mathrm{Ca}, \mathrm{Sr}, \mathrm{Fe}$, $\mathrm{Si}, \mathrm{MGS}$ ) on the reference lithotheque and the Inopos wall measures (black 
circles). Colors indicate locations: blue for Delos, orange for Tinos, green for Naxos, red for Paros, pink for Hymettus. Sample nomenclature is explained in $\S 3.1$. Arrows indicate in which direction ellipses are deported depending on the variable value; high values deport the ellipse in the arrow direction whereas low values deport the ellipse in the opposite way

Fig. 7 Principal Component Analysis (PCA) diagram using 5 variables ( $\mathrm{Ca}, \mathrm{Sr}, \mathrm{Fe}$, $\mathrm{Si}, \mathrm{MGS}$ ) on the reference lithotheque and the Philippe $\mathrm{V}$ portico measures (black circles). Colours indicate locations: blue for Delos, orange for Tinos, green for Naxos, red for Paros, pink for Hymettus. Sample nomenclature is explained in $\S 3.1$. Arrows indicate in which direction ellipses are deported depending on the variable value, high values deport the ellipse in the arrow direction whereas low values deport the ellipse in the opposite way

Supplementary material: Table 1 Data table referencing the result of pXRF and ICP analyses on database powders used to build linear regressions of figure 3 in supplementary material. Sample names refer to the geological sample presentation in $\$ 3.1$ and letters $\mathrm{a} / \mathrm{b} / \mathrm{c}$ are indicated when more than one powder were analysed for a same marble. Values are given in ppm

Supplementary material: Fig. 1 Archaeological site in Delos (map created from EFA archaeological map of Delos). Circles 1 and 2 locate Philip V portico and Inopos reservoir respectively. Dotted line represents the actual coastline

Supplementary material: Fig. 2 Diagrams of six element concentrations obtained via XRF analysis on the reference lithotheque on a weathered surface (grey line) and a fresh sawn surface (dark line). Abscisse abbreviations refer to sample provenances detailled in $\$ 3.1$

Supplementary material: Fig. 3 Calibration diagram of the $\mathrm{Ca}, \mathrm{Sr}, \mathrm{Si}, \mathrm{Fe}$ using pXRF and ICP measures on the powdered reference database

\section{References}

Altherr, R., and Siebel, W., 2002, I-type plutonism in a continental backarc setting: Miocene granitoids and monzonites from the Central Aegean Sea, Greece, Contributions to Mineralogy and Petrology, 143, 397-415. 
Antonelli, F., and Lazzarini, L., 2015, An updated petrographic and isotopic reference database for white marbles used in antiquity, Rendiconti Lincei, 26, 399-413.

Attanasio, D., Brilli, M., and Ogle, N., 2006, The isotopic signature of classical marbles, L'ERMA diBRETSCHNEIDER, Rome.

Blake, M. C., Bonneau, M., Geyssant, J., Kienast, J. R., Lepvrier, C., Maluski, H., and Papanikolaou, D., 1981, A geologic reconnaissance of the Cycladic blueschist belt, Greece, GSA Bulletin, 92, 247-54.

Brilli, M., Cavazzini, G., and Turi, B., 2005, New data of $87 \mathrm{Sr} / 86 \mathrm{Sr}$ ratio in classical marble: An initial database for marble provenance determination, Journal of Archaeological Science, 32, 1543-51. https://doi.org/10.1016/j. jas.2005.04.007

Calligaro, T., Coquinot, Y., Guerra, M. F., Herrmann, J. J., Laugier, L., and den Hoek, A. V., 2013, Dolomitic marble from Thasos at the louvre, Open Journal of Archaeometry, 1, 14.

Capedri, S., and Venturelli, G., 2004, Accessory minerals as tracers in the provenancing of archaeological marbles, used in combination with isotopic and petrographic data*, Archaeometry, 46, 517-36. https://doi.org/10.1111/j.14754754.2004.00171.x

Carignan, J., Engi, M., and Rickli, M., 1997, Tectonometamorphic evolution of SE Tinos, Cyclades, Greece, Schweiz Miner, Petrogr Mitt.

Carignan, J., Hild, P., Mevelle, G., Morel, J., and Yeghicheyan, D., 2001, Routine analyses of trace elements in geological samples using ftow injection and low pressure on-line liquid chromatography coupled to ICP-MS: A study of geochemical reference materials BR, DR-N, UB-N, AN-G and GH, Geostandards Newsletter, 25, 187-98.

Chatzidakis, P., Katzsikis, G., and Matarangas, M., 1997, Delos sacred Greece: Characterization of the building stones, their origin an decay factor. In Marinos, P. G., Koukis, G. C., Tsiambaos, G. C. \& Stoumaras, G. C., (Eds.) In Engi-neering geology and the environment. Leiden: CRC Press / Balkema, 3089-94.

Cayeux, L., 1911, Description physique de l'île de Délos. Exploration archéologique de Délos (Physical description of Delos Island. Delos Archaeological exploration). Fontemoing et Cie, Paris.

Davis, J. C., 1986, Statistics and data analysis in geology, 2nd: edn. Wiley, New York.

Denèle, Y., Lecomte, E., Jolivet, L., Lacombe, O., Labrousse, L., Huet, B., and Le Pourhiet, L., 2011, Granite intrusion in a metamorphic core complex: 
The example of the Mykonos laccolith (Cyclades, Greece), Tectonophysics, 501, 52-70.

Ecole Française d'Athènes, 2005, Guide de Délos, 4th: edn. De Boccard, Paris.

Faure, M., Bonneau, M., and Pons, J., 1991, Ductile deformation and syntectonic granite emplacement during the late Miocene extension of the Aegea (Greece), Bulletin de la Société Géologique de France, 162, 3-11.

Forster, N., and Grave, P., 2012, Non-destructive PXRF analysis of museum-curated obsidian from the near east, Journal of Archaeological Science, 39, 728-36.

Fraisse, P., and Kozelj, T., 1991, Une carrière de marbre au Sud-Est du Cynthe, Bulletin de Correspondance Hellenique, 115, 283-96. https://doi.org/10.3406/bch.1991.4684

Garcia-Vallès, M., Urzi, C., Leo, F. D., Salamone, P., and Vendrell-Saz, M., 2000, Biological weathering and mineral deposits of the Belevi marble quarry (Ephesus, Turkey), Int. Biodeterior. Biodegrad., Biodeteriation of Culture Property, 2(Part 1 46), 221-7. https://doi.org/10.1016/S0964-8305(00)00076-7

Green, W. A., Young, S. M. M., Van der Merwe, N. J., and Hermann, J. J. Jr., 2002, Source tracing marble: Trace element analysis with inductively coupled plasma-mass spectrometry, in ASMOSIA V. interdisciplinary studies on ancient stone. J. Herrmann, N. Herz, and R. Newman (Eds.), 132-42, Archetype Publications, London.

Hadjidakis, P., Matarangas, D., and Varti-Matarangas, M., 2003, Ancient quarries in Delos, Greece. ASMOSIA VII, Proceedings of the 7th International Conference of Association for the Study of Marble and Other Stones in Antiquity. De Boccard, Paris.

Jolivet, L., Rimmelé, G., Oberhänsli, R., Goffé, B., and Candan, O., 2004, Correlation of syn-orogenic tectonic and meta- morphic events in the Cyclades, the Lycian nappes and the Menderes massif. Geodynamic implications, Bulletin de la Société Géologique de France, 175, 217-38. https://doi.org/10.2113/175.3.217

Jolivet, L., Lecomte, E., Huet, B., Denèle, Y., Lacombe, O., Labrousse, L., Le Pourhiet, L., and Mehl, C., 2010, The north Cycladic detachment system, Earth and Planetary Science Letters, 289, 87-104. https://doi.org/10.1016/j. eps1.2009.10.032

Karydas, A. G., Brecoulaki, H., Bourgeois, B., and Jockey, P., 2009, Insitu X-ray ftuorescence analysis of raw pigments and traces of polychromy on Hellenistic sculpture at the archaeological museum of Delos, BCH Supplement, 51, 811-29. 
Keay, S., 1998. The geological evolution of the Cyclades, Greece: Constraints from SHRIMP U-Pb geochronology. $\mathrm{PhD}$ thesis. https://doi.org/10.25911/5d66671ad2b2f

Kokkoru-Aleura, G., Ethnikon kai Kapodistriakon Panepistēmion., Tomeas Archaiologias kai Historias tēs Technēs, 2014. Corpus archaiōn latomeiōn: Latomeia tu elladiku chōru apo tus proïstorikus eōs tus mesaiōnikus chronus, Panepistēmio Athēnōn, Philosophikē Scholē, Tomeas Archaiologias Kai Istorias tēs Technēs, Athēna.

La Russa, M., Ruffolo, S., Ricca, M., Ricci, S., Davidde, B., Barca, D., and Capristo, V., 2013, A multidisciplinary approach to the study of underwater artefacts: The case of a Tritone Barbato marble statue (Grotta Azzurra, Island of Capri, Naples). Periodico di Mineralogia, 82, 101-11.

Lapuente, P., Turi, B., and Blanc, P., 2000, Marbles from Roman Hispania: Stable isotope and cathodoluminescence characterization. Applied Geochemistry, 15, 1469-93.

Lazzarini, L., Moschini, G., and Stievano, B. M., 1980, A contribution to the identification of Italian, Greek and Anatolian marbles though a petrological study and the evaluation of $\mathrm{Ca} / \mathrm{Sr}$ ratio, Archaeometry, 22, 173-83. https://doi.org/ 10.1111/j.1475-4754.1980.tb00940.x

Lee, J., and Lister, G. S., 1992, Late Miocene ductile extension and detachment faulting, Mykonos, Greece, Geology, 20,121-4.

Lepsius, R., 1890, Griechische Marmorstudien, Akademie der Wissenschaften, Berlin, Könige.

Lucas, I., 1999. Le pluton de mykonos-delos-rhenee (cyclades, grece) : Un exemple de mise en place synchrone de l'extension crustale (thesis). Orléans. $\mathrm{PhD}$ thesis.

Magrini, D., Attanasio, D., Bracci, S., Cantisani, E., and Prochaska, W., 2016, Innovative application of portable X-ray ftuorescence (XRF) to identify Göktepe white marble artifacts, Archaeological and Anthropological Sciences, $10,1141-52$.

Matthews, K. J., 1997, The establishment of a data base of neutron activation analyses of white marbles, Archaeometry, 39, 321-32.

Parra, T., Vidal, O., and Jolivet, L., 2002, Relation between the intensity of deformation and retrogression in blueschist metapelites of Tinos Island (Greece) evidenced by chlorite-mica local equilibria, Lithos, 63, 41-66. https://doi.org/ 10.1016/S0024-4937(02)00115-9

Pensabene, P., Antonelli, F., Lazzarini, L., and Cancelliere, S., 2012, Provenance of marble sculptures and artifacts from the so-called Canopus and 
other buildings of "villa Adriana" (Hadrian's villa - Tivoli, Italy), Journal of Archaeolog-ical Science, 39, 1331-7. https://doi.org/10.1016/j.jas.2012.01.015

Poretti, G., Brilli, M., De Vito, C., Conte, A. M., Borghi, A., Günther, D., and Zanetti, A., 2017, New considerations on trace elements for quarry provenance investigation of ancient white marbles, Journal of Cultural Heritage, 28, 16-26.

Potts, P. J., Webb, P. C., and Watson, J. S., 1984, Energy-dispersive x-ray ftuorescence analysis of silicate rocks for major and trace elements, X-Ray Spectrometry, 13, 2-15. https://doi.org/10.1002/xrs.1300130103

Ricca, M., Belfiore, C. M., Ruffolo, S. A., Barca, D., De Buergo, M. A., Crisci, G. M., and La Russa, M. F., 2015, Multi-analytical approach applied to the provenance study of marbles used as covering slabs in the archaeological submerged site of Baia (Naples, Italy): The case of the "Villa con ingresso a protiro". Applied Surface Science, 357, 1369-79. https://doi.org/10.1016/j.apsusc.2015.10.002

Ricca, M., Russa, M. F. L., Ruffolo, S. A., Davidde, B., Barca, D., and Crisci, G. M., 2014, Mosaic marble tesserae from the underwater archaeological site of Baia (Naples, Italy): Determination of the provenance, European Journal of Mineralogy, 26, 323-31. https://doi.org/10.1127/0935-1221/2014/0026-2354

Shackley, M. S., 2011, An introduction to X-ray ftuorescence (XRF) analysis in archaeology, in X-ray fluorescence spectrometry (XRF) in Geoarchaeology. M. S. Shackley (Ed.), 7-44. Springer, New York.

Tykot, R., Hermann, J. J., Van der Merwe, N. J., Newman, R., and Allegretto, K. O., 2002, 'Thasian' Marble Sculptures in European and American Collections: Isotopic and other Analyses, ASMOSIA V: Interdisciplinary Studies on Ancient Stone. Proceedings of the Fifth International Conference of the Association for the Study of Marble and Other Stones in Antiquity, 188-95. Archetype Publications Ltd, London.

Vallois, R., 1923, Le portique de Philippe. Les portiques au sud du Hiéron. EAD. VII.

De

Boccard,

Paris 

